\title{
Cannabinoid receptor CB1 mediates baseline and activity-induced survival of new neurons in adult hippocampal neurogenesis
}

\author{
Susanne A Wolf*1,2, Anika Bick-Sander1, Klaus Fabel4, Perla Leal-Galicia44, Svantje Tauber², Gerardo Ramirez- \\ Rodriguez ${ }^{1,3}$, Anke Müller1, Andre Melnik2 , Tim P Waltinger2, Oliver Ullrich² and Gerd Kempermann*1,4
}

\begin{abstract}
Background: Adult neurogenesis is a particular example of brain plasticity that is partially modulated by the endocannabinoid system. Whereas the impact of synthetic cannabinoids on the neuronal progenitor cells has been described, there has been lack of information about the action of plant-derived extracts on neurogenesis. Therefore we here focused on the effects of $\triangle 9$-tetrahydrocannabinol (THC) and Cannabidiol (CBD) fed to female C57BI/6 and Nestin-GFP-reporter mice on proliferation and maturation of neuronal progenitor cells and spatial learning performance. In addition we used cannabinoid receptor 1 (CB1) deficient mice and treatment with CB1 antagonist AM251 in Nestin-GFP-reporter mice to investigate the role of the CB1 receptor in adult neurogenesis in detail.

Results: THC and CBD differed in their effects on spatial learning and adult neurogenesis. CBD did not impair learning but increased adult neurogenesis, whereas THC reduced learning without affecting adult neurogenesis. We found the neurogenic effect of CBD to be dependent on the CB1 receptor, which is expressed over the whole dentate gyrus. Similarly, the neurogenic effect of environmental enrichment and voluntary wheel running depends on the presence of the $C B 1$ receptor. We found that in the absence of $C B 1$ receptors, cell proliferation was increased and neuronal differentiation reduced, which could be related to CB1 receptor mediated signaling in Doublecortin (DCX)-expressing intermediate progenitor cells.
\end{abstract}

Conclusion: CB1 affected the stages of adult neurogenesis that involve intermediate highly proliferative progenitor cells and the survival and maturation of new neurons. The pro-neurogenic effects of CBD might explain some of the positive therapeutic features of CBD-based compounds.

\section{Background}

The recreational use of cannabis is often justified by extrapolation from the unquestionable physiological role of endocannabinoids in brain function [1], and the successful and beneficial manipulation of the endocannabinoid system for medical purposes [2,3] by plant extracts from cannabis sativa or synthetic agonist and antagonists specific for cannabinoid receptor1 or 2 (CB1, CB2) [4,5]. The abuse of cannabis can be associated with detrimental

\footnotetext{
*Correspondence: susanne.wolf@anatom.uzh.ch, gerd.kempermann@crt-dresden.de ${ }^{1}$ Max Delbrück Center for Molecular Medicine (MDC) Berlin-Buch, and Volkswagenstiftung Research Group, Department of Experimental Neurology, Charité University Medicine, Berlin, Germany

2 Institute of Anatomy, University of Zurich, Zurich, Switzerland

Full list of author information is available at the end of the article
}

long-term consequences, for example an increased risk of developing memory impairments [6,7].

The process of generating new neurons throughout life in the hippocampus probably plays a role in learning and memory processes [8], and impairment of adult hippocampal neurogenesis is thought to be part of the pathogenesis of neurodegenerative disorders like dementia, epilepsy and schizophrenia $[9,10]$. Adult neurogenesis is a particular example of brain plasticity as it involves the integration of entire cells [11,12]. Due to its physiological role in brain plasticity the endocannabinoid system might contribute to the control of adult hippocampal neurogenesis in health and disease. A number of arguments point into the direction that cannabinoids might exert some of 
their actions via their effects on adult neurogenesis (reviewed in [13]).

The therapeutic activities of cannabinoids include analgesia, immuno-suppression, mood stabilization, antiemesis, bronchodilatation and neuroprotection [14]. Because of the psychotropic effects of some cannabinoids, their clinical use is limited. Cannabidiol (CBD) is the main non-psychotropic compound of the plant cannabis sativa and belongs to the group of exogenous cannabinoids [15]. Due to its lack of psychoactive actions, CBD represents one of the most promising candidates for clinical application [14]. CBD was shown to act anti-psychotic in Parkinson's disease and as a monotherapy in treatment-resistant schizophrenia $[16,17]$. The neuroprotective effects of CBD have been linked with its antioxidant activity [18]. Evidence emerges that CBD realizes some of its effect via the classical CB receptors [19].

Many constituents of the endogenous cannabinoid system like the $\mathrm{CB} 1$ and $\mathrm{CB} 2$ receptors and their endogenous ligands Anandamide (AEA) and 2arachidonylglycerol (2-AG) as well as the AEA-degrading enzyme fatty acid amide hydrolase (FAAH) and the 2-AG synthesizing enzyme diacylglycerol lipases are found in neuronal developmental and adult neurogenesis [20-22].

Several studies investigating the role of the cannabinoid system in adult neurogenesis found that stimulation of CB1 seemed to either increase or decrease adult neurogenesis [21,23]. For example, the synthetic agonist HU210 decreased the number of intermediate progenitor cells in one study [24], but promoted neuronal differentiation in another [25]. In other studies, CB1 receptor activation promoted precursor cell proliferation and the generation of neurospheres ex vivo, which was abrogated in CB1deficient precursor cells, and proliferation of hippocampal precursor cells was increased in FAAH deficient mice $[21,23,26]$. Likewise, in adult CB1-deficient mice, neural progenitor proliferation is decreased. In addition, endocannabinoid signaling controls neural progenitor differentiation in the adult brain by promoting astroglial differentiation of newly born cells [23]. Along the same line, Rueda et al. have shown that the endocannabinoid AEA inhibited neuronal progenitor cell differentiation through attenuation of the extracellular signal regulated kinase pathway in vitro, and that adult neurogenesis in the dentate gyrus was significantly decreased by the AEA analogue methanandamide and increased by the CB1 antagonist SR141716 [27].

Precursor cell proliferation is a relatively non-specific measure of neurogenesis and not identical to the net production of new neurons. Progenitor cell proliferation is, for example, increased after epileptic seizures without necessarily leading to functional neurogenesis [28]. The incorporation of the progenitor cell into the neuronal network is impaired after seizures despite a high proliferation rate [29]. In the study by Jin et al. only BrdU incorporation was measured without further phenotyping the labeled cells and only cell proliferation was directly addressed [30]. However, they reported increased cell proliferation after treatment with CB1 antagonists SR141716 and AM251, which is in line with the findings by Rueda at al. [27]. In addition, they showed that SR141716 enhances cell proliferation via the vanillin receptor 1 [30]. The absence of the CB1 receptor resulted again in decreased proliferation.

The confusion that emerges when comparing the studies could be explained by differences in the study design, compounds used, sex of the animals, duration of application, and the readout parameters for "adult neurogenesis". Moreover, in the context of adult neurogenesis, only synthetic compounds interacting with the endogenous cannabinoid system have been investigated so far. It has been speculated that also plant-derived cannabinoids might have an impact on neurogenesis, but no data exist to date. The sole exception is a brief study reporting no effects on cell proliferation in general [31].

In our study we therefore first examined the effects on adult neurogenesis in female $\mathrm{C} 57 \mathrm{Bl} / 6$ mice by pharmaceutical extracts enriched with $\Delta 9$-tetrahydrocannabinol (THC) or Cannabidiol (CBD) directly derived from the plant cannabis sativa. Since THC's and CBD's mode of actions are partly CB1-dependent [19,32], we then looked at the time course (including proliferation and net-neurogenesis) of the maturation process of neuronal precursor cells in CB1-/- C57Bl/6 female mice and the impact of the CB1 antagonist AM251.

\section{Results}

\section{Chronic THC treatment impairs spatial learning}

Either THC- or CBD-enriched or control (CTR) diet was fed to female $\mathrm{C} 57 \mathrm{Bl} / 6$ or Nestin-GFP-reporter mice. The food intake and the weight gain over the period of 6 weeks were similar in all the treatment groups (see additional file 1, Additional file 2). To examine the impact of chronic THC vs. CBD treatment on spatial memory, we tested the three experimental groups (THC, CBD, CTR) in the Morris water maze (MWM). The task in the MWM is to navigate to a hidden platform using spatial cues in the room. As shown in figure $1 \mathrm{~A}, \mathrm{THC}$ mice were slower in finding the hidden platform over the whole acquisition period (repeated measures ANOVA, $\mathrm{F}_{2,20}=3.49 ; \mathrm{p}=$ $0.0014)$. In addition, THC mice showed a significantly impaired performance during the reversal learning (with the hidden platform at a new position) with regard to both latency (THC: $36.13+/-10.94$, CTR: $16.88+/-4.21$, $\mathrm{p}=0.002$, ANOVA, $\mathrm{F}_{2,20}=3.49$, Fig. $1 \mathrm{~A}$ ) and distance to platform (THC: $49.4 \pm 6.76$, CTR: $31.93 \pm 2.94, p=0.002$, 

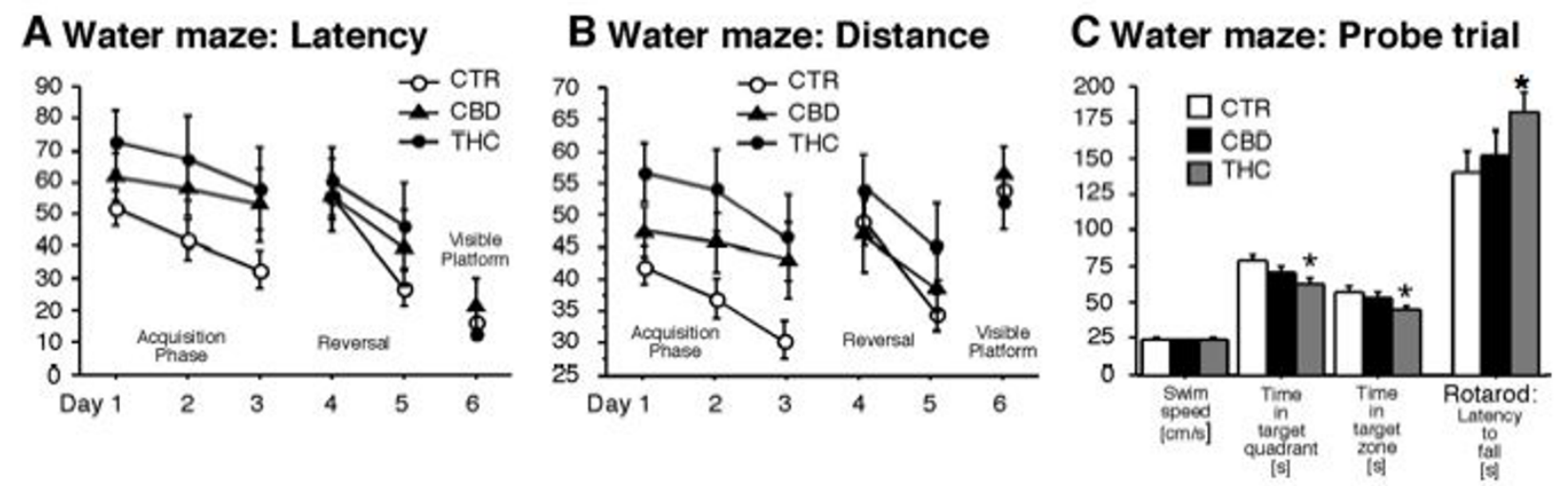

Figure 1 Spatial learning was impaired after THC treatment. C57BI/6 female mice were either fed with food supplemented with THC-rich or CBDrich plant extracts or a control diet. Spatial memory was tested after 6 weeks of treatment. THC mice were slower in finding the hidden platform over the whole acquisition period and during the reversal learning, with regard to both latency (A) and distance (B) to platform. All three groups performed at the same level when the platform was made visible on day 6 to test for possible visual impairments and the general ability to perform the task. A Rotarod test to measure general locomotor function and fitness was performed on day 7 . The THC group performed better than CTR (C); ${ }^{*} p \leq 0.05$.

ANOVA, $F_{2,20}=3.49$; Fig. $\left.1 \mathrm{~B}\right)$. All three groups performed at the same level when the platform was made visible on day 6 to test for possible visual impairments and the general ability to perform the task (Fig. 1A, B). The impaired learning performance of the THC-treated mice was also reflected by the shorter time the animals spent in the old target quadrant and target zone during the probe trial at day 4 (Fig. 1C). A rotarod test to assess general locomotor functions and fitness was performed on day 7. The THC group performed better than CTR (CTR $138.47 \pm 25.844 \mathrm{~s}$, THC group $180.82 \pm 26.17 \mathrm{~s} ; \mathrm{p}=$ 0.0046, ANOVA, $\mathrm{F}_{2,16}=3.634$; Fig. 1C), whereas CBD performed at control level. Therefore, the decreased performance of THC mice in the water maze could not be attributed to a reduced general fitness.

CBD mice showed some (statistically not significant, $\mathrm{p}$ $=0.124 ; \mathrm{F}_{2,20}=3.49$; Fig. $1 \mathrm{~A}, \mathrm{~B}$ ) impairment during acquisition. During the probe trial (Fig. 1C) and the reversal they performed very similar to CTR.

\section{Chronic THC treatment decreases adult neurogenesis}

We have previously reported that adult hippocampal neurogenesis can be linked to aspects of the acquisition phase during water maze learning [33] with a particular contribution to reversal performance $[34,35]$. We did not find a specific reversal phenotype in the present study but nevertheless asked whether a decrease in adult neurogenesis, possibly matching the observed alterations in water maze performance, might be found after THC or CBD treatment.

We found that chronic THC application reduced precursor cell proliferation in the DG (THC vs. CTR: $2018 \pm$ $96 ; 2515 \pm 180 ; n=5 ; p=0.037$, Fig. 2 A) without affecting cell survival or net neurogenesis. In contrast, however, despite decreasing proliferation, CBD increased cell survival (proliferation: CBD vs. CTR: $2083 \pm 102$ vs. $2515 \pm$ 180; $\mathrm{n}=5 ; \mathrm{p}=0.0358$; survival: CBD vs. CTR: $756 \pm 28$ vs. $180 \pm 21 ; \mathrm{n}=5 ; \mathrm{p}=0.0012$; Fig. $2 \mathrm{~A}$ ).

In both, THC and CBD groups we found a minimal reduction in the number of BrdU-labeled type-1/2a cells, i.e. Nestin-GFP-positive, Doublecortin (DCX)-negative cells, but a significant reduction at the level of the type- $2 \mathrm{~b}$ cells (Nestin-GFP-positive, DCX-positive; THC vs. CTR: $502 \pm 83$ vs. $748 \pm 78 ; n=5 ; p=0.028$; CBD vs. CTR: 507 \pm 62 vs. $748 \pm 78 ; n=5 ; p=0.032$; Fig. $2 B$ ). In THC the number of DCX-positive/Nestin-GFP-negative cells was also reduced (THC vs. CTR: $113 \pm 19$ vs. $249 \pm 26 ; n=5$; $\mathrm{p}=0.004$; Fig. $2 \mathrm{~B}$ ), possibly indicating that $\mathrm{THC}$ might not increase net neurogenesis but nevertheless accelerate the transition through the DCX-positive stage. For an overview of the maturation stages see below. A representative $\mathrm{BrdU} / \mathrm{NeuN}$ staining is shown in figure $2 \mathrm{C}$.

There was, however, a significant increase in the production of BrdU/NeuN-positive cells in the CBD group (CBD vs. CTR: $297 \pm 32$ vs. $146 \pm 23 ; n=5 ; p=0.001$; Fig. $2 \mathrm{~A}, \mathrm{~B})$, suggesting that in this case an accelerated transition through the DCX stage might result in more neurons, an effect absent in the case of THC.

Taken together THC treated mice showed reduced water maze performance, albeit not the presumably neurogenesis-related reversal impairment, and reduced adult neurogenesis, whereas CBD mice did not. On the other hand our results pointed to a positive effect of CBD on adult neurogenesis that we now intended to explore further. 


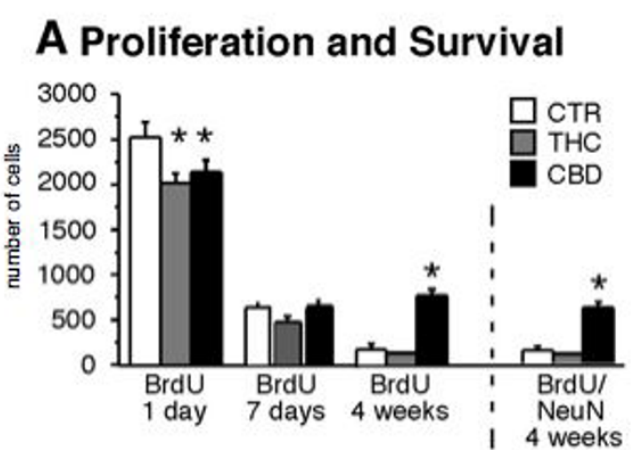

\section{B Phenotypes at 7 days}

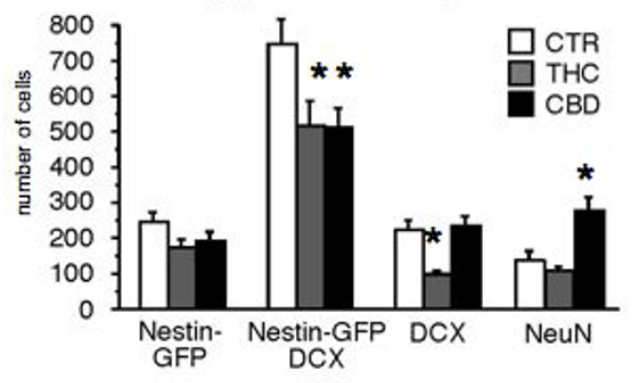

\section{BrdU and NeuN labeling}
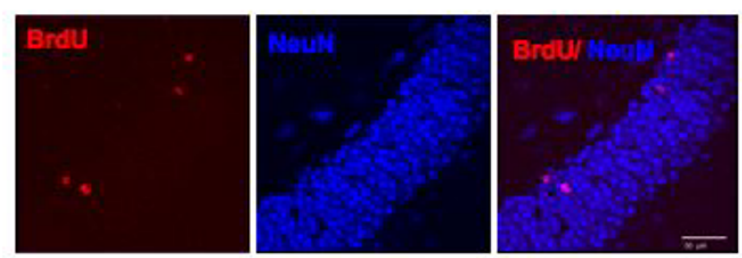

Figure 2 CBD treatment enhanced adult neurogenesis. BrdU cells reflect the population of proliferating cells at a given period of time. Proliferation was measured $24 \mathrm{~h}$ after BrdU injection, while survival was measured 4 weeks after BrdU injection. NeuN/BrdU double positive cells at 4 weeks after BrdU injection are the neurons that were generated and survived during the period of 4 weeks. THC treatment for 6 weeks reduced cell proliferation without affecting neuronal survival. In contrast, $C B D$ treatment decreased proliferation as well, but increased neuronal cell survival seen at 4 weeks after BrdU injection. (A). Animals expressing Nestin, an early marker of neuronal maturation, under a GFP promotor were also fed with THC-rich, CBD-rich, or control (CTR) diet for 6 weeks. The animals were assessed at 7 days after BrdU injection to evaluate the early stages of neurogenesis. In both THC and CBD groups we found a minimal reduction in the number of BrdU-labeled type-1/ 2a cells (Nestin-GFP-positive, DCX-negative) but a significant reduction on the level of the type-2b (Nestin-GFP-positive, DCX-positive). In THC the number of DCX-positive/Nestin-GFP-negative cells was also reduced. There was a significant increase in the production of BrdU/ NeuN-positive cells in the CBD group (B); ${ }^{*} p \leq 0.05$. In (C) we show a representative micrograph of BrdU labeled cells (red) within the granule cell layer labeled with NeuN (blue) of the dentate gyrus. The section is one out of nine throughout one hippocampus of a female C57BI/6 animal that received $3 \mathrm{BrdU}$ injections 4 weeks prior to analysis. The section is $40 \mu \mathrm{m}$ thick and the scale bar is $50 \mu \mathrm{m}$.

\section{CBD effects on adult neurogenesis are absent in CB1 -/-} mice

We next asked whether these CBD-mediated effects on BrdU incorporation might be mediated by the CB1 receptor, which is highly expressed in the dentate gyrus and fed $\mathrm{CBD}$ to $\mathrm{CB} 1-/$ - mice and their wild type litter mates in parallel for 6 weeks. We found that the increase in BrdU cell survival induced by CBD was abolished in CB1-/mice (Fig. 3; WT/CBD vs. CB1-/-/CBD: $716 \pm 83$ vs. $152 \pm$ $28 ; \mathrm{n}=5 ; \mathrm{p}=0.001)$. CB1-/- mice showed a decrease in the number of BrdU cells. This decrease in CB1-/- has already been described in the literature. But we could here show a similar effect of $\mathrm{CB} 1-/$ - at the survival time point at 4 weeks after BrdU application (CB1-/- vs. WT: $180 \pm 15$ vs. $368 \pm 21 ; \mathrm{n}=5 ; \mathrm{p}=0.002$ ).

\section{CB1 is expressed during the DCX-stage of adult hippocampal neurogenesis}

Given this relevance of the CB1 receptor for the observed adult neurogenesis phenotype we next asked, which cells would express the CB1 receptor in the course of adult neurogenesis. We used hippocampal sections from untreated female Nestin-GFP-reporter mice. Based on these mice we have previously proposed a model of neuronal development in the adult hippocampus [36-38].

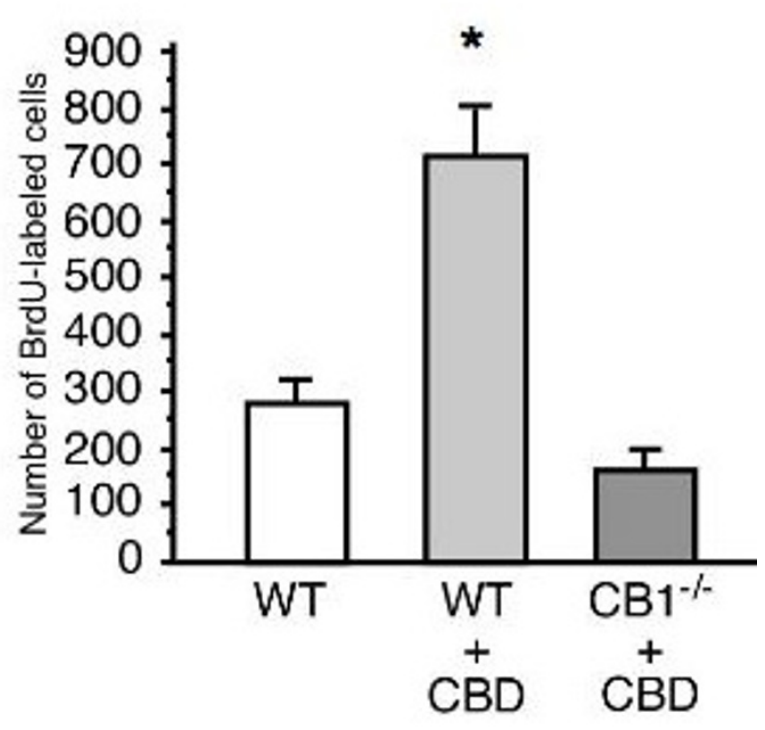

Figure 3 CBD effect was absent in CB1-/- mice. We fed additional wild type and $\mathrm{CB} 1 \%$ mice with $\mathrm{CBD}$ for 6 weeks. We found that the increase in cell survival induced by CBD was abolished in $\mathrm{CB} 1 \%$ mice; ${ }^{*} \mathrm{P}$ $\leq 0.05$. 
From a Nestin-GFP-positive radial glia-like putative stem cell (type-1) development proceeds over a population of highly proliferative Nestin-GFP-positive intermediate progenitor cells with glial properties, but lacking the radial morphology (type-2a) and a similarly proliferative progenitor cell which is still Nestin-GFP-positive but also expresses DCX (as well as, for example, Prox1 and NeuroD1) and thus shows signs of neuronal determination (type-2b). Migratory, neuroblast-like type-3 cells are DCX-positive but do not express Nestin-GFP anymore. They show limited proliferation. After this stage, cells go through a postmitotic maturation stage, during which the new neurons extend their neurites and which is associated with the transient expression of Calretinin [37,39] and of the lasting postmitotic neuronal marker NeuN.

Based on this model of adult hippocampal neurogenesis and the sequence of cellular morphology and marker expression, we found CB1-receptor expression spread over the entire dentate gyrus and the whole course of neurogenesis (Fig. 4A). However, it appeared that comparatively less staining was observed in the population of Nestin-positive type 1 cells (Fig. 4B) and type 2a cells. However, there was a tendency towards a stronger signal in cells expressing DCX (type $2 \mathrm{~b} / 3$ cells; Fig. $4 \mathrm{C}$, D), postmitotic new neurons that express Calretinin (Fig. 4E, F) and NeuN-positive mature new neurons (Fig. 4G, H). This implies that CB1 expression would increase with the degree of differentiation from type-2b cells onwards.

\section{CB1 mRNA expression is induced by activity}

We subjected adult untreated female $\mathrm{C} 57 \mathrm{Bl} / 6$ mice to either voluntary wheel running (RUN) or enriched environment (ENR). One group was housed in conventional cages (CTR). Type-2 cells are highly regulated cells in vivo and are influenced by behavioral activity. We have previously shown that both environmental enrichment and voluntary physical activity induce adult hippocampal neurogenesis while having differential effects on the type2 progenitor cells [40]. We here confirmed this observation at the level of Nestin-mRNA expression, showing that RUN but not ENR increased Nestin mRNA (Fig. 5C CTR vs. ENR: $8 \pm 2.2$ vs. $6 \pm 1.7 ; \mathrm{n}=6 ; \mathrm{p}=0.214$; CTR vs. RUN: $8 \pm 2.2$ vs. $13 \pm 5.1 ; \mathrm{n}=6 ; \mathrm{p}=0.041)$. These findings are consistent with the counts of BrdU positive cells (Fig. 5A CTR vs. ENR: $1184 \pm 81$ vs. $1462 \pm 35 ; \mathrm{n}=5 ; \mathrm{p}=0.051$; CTR vs. RUN $1184 \pm 81$ vs. $2197 \pm 94 ; \mathrm{n}=5 ; \mathrm{p}=0.002$ ). In the same samples, we found that both RUN and ENR increased the expression of CB1 receptor mRNA in the hippocampus (Fig. 5C; CTR vs. ENR: $4 \pm 1.8$ vs.10.5 \pm 0.8 ; $\mathrm{n}=6 ; \mathrm{p}=0.0001$; CTR vs. RUN: $4 \pm 1.8$ vs. $12.5 \pm 1.6 ; \mathrm{n}=$ $6 ; \mathrm{p}=0.0001$ ). This supported our result from immunohistochemistry with regard to the expression of CB1 on neuronal progenitor cells. We next wanted to know,
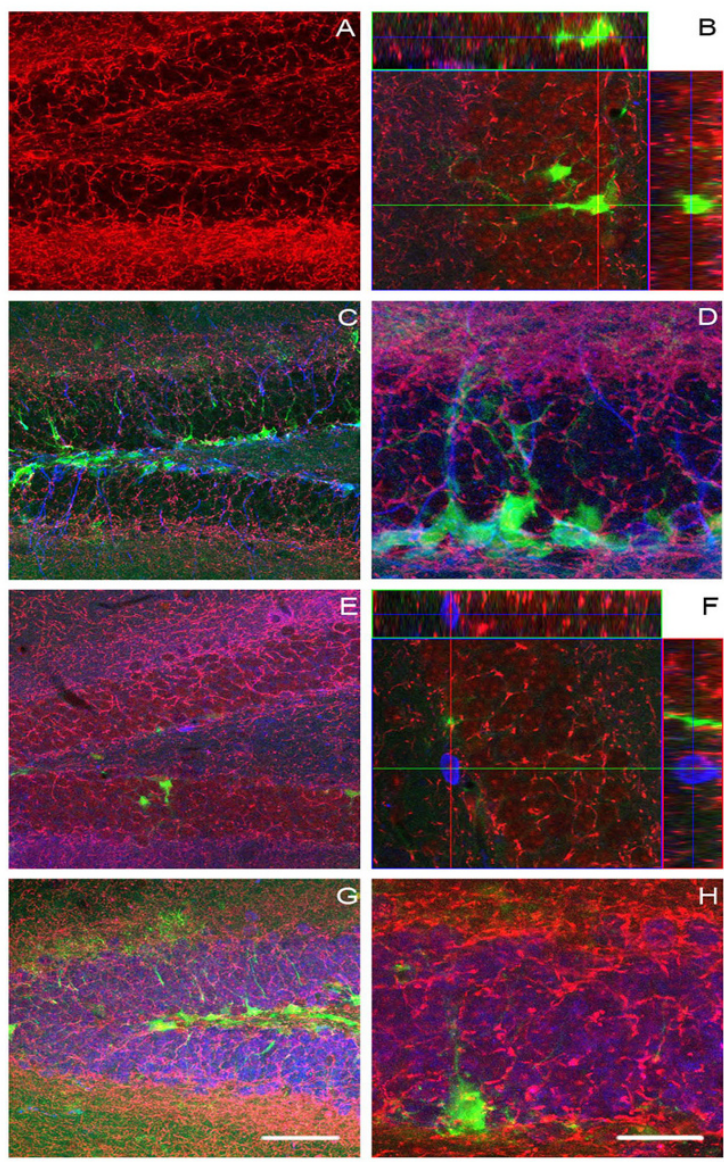

Figure 4 Cannabinoid receptor 1 immunoreactivity in the dentate gyrus. We here show representative photomicrographs of immunofluorescent staining of $40 \mu \mathrm{m}$ thick mouse brain sections. CB1 immunoreactivity appears in red, Nestin-GFP in green, DCX, Calretinin (CR) and NeuN in Blue. The confocal scanning photomicrograph, $1 \mu \mathrm{m}$ thickness, 40x magnification, shows that the CB1 receptor (red) is highly expressed in the dentate gyrus (A). The three-dimensional reconstruction of z-series of 8 confocal scanning photomicrograph (1.5 $\mathrm{mm}$ each) in shown in (B). The co-localization with Nestin-GFP (green) was found in some of cells with rounded morphology, less in the radial glia-like type-1 cells as shown in detail using orthogonal projections. The projection of 11 (C) and 13 (D) confocal scanning micrographs (1,5 $\mu \mathrm{m}$ thickness) reveals that DCX-positive cells (blue) show co-localization with the CB1 receptor (red). The $113 \times$ magnification shows in more detail the expression of CB1 receptor in DCX-positive cells (D). The confocal scanning photomicrograph, $1 \mu \mathrm{m}$ thickness, magnification $40 \times$ shows a co-localization of Calretinin-positive staining with $\mathrm{CB} 1$ receptor (E). The three-dimensional reconstruction of z-series of 6 confocal scanning photomicrographs (1.5 mm each), 113× magnification show that Calretinin-positive cells (blue) are surrounded by CB1 receptor (red). The three-dimensional reconstruction of z-series of 13 $(\mathrm{G})$ and $9(\mathrm{H})$ confocal scanning photomicrographs $(1.5 \mu \mathrm{m}$ each) show immuno-reactivity to CB1 (red) in NeuN (blue) cells. The $113 \times$ magnification shows the co-localization in more detail $(\mathrm{H})$. The representative scale bar is in $\mathrm{G}(50 \mathrm{~mm})$ for $\mathrm{A}, \mathrm{C}, \mathrm{E}$, and $\mathrm{G}$; it is in $\mathrm{H}(20 \mathrm{~mm})$ for $\mathrm{B}, \mathrm{D}, \mathrm{F}$, and $\mathrm{H}$. 


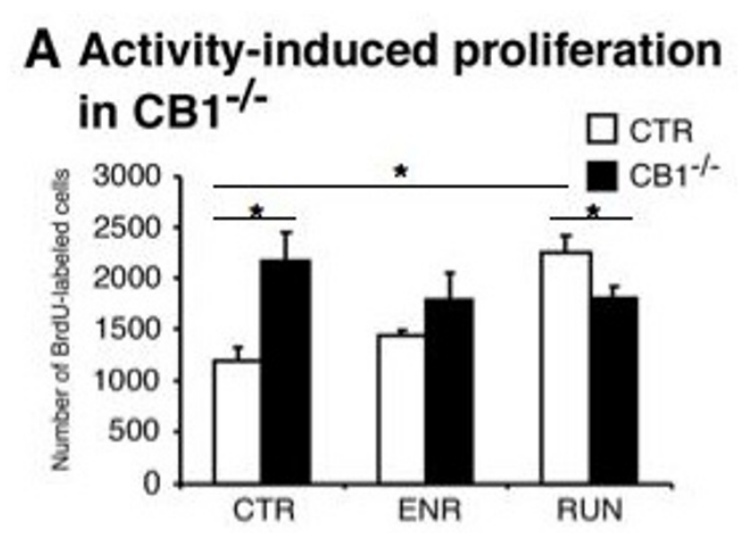

B Activity-induced survival

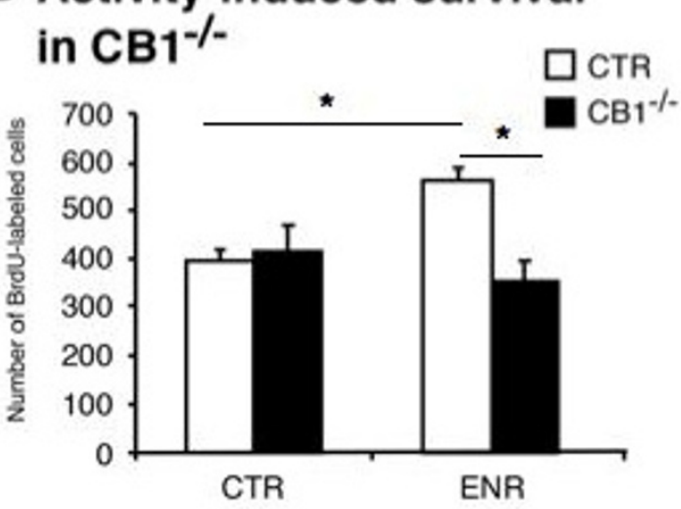

\section{Activity-induced modulation of CB1 expression}

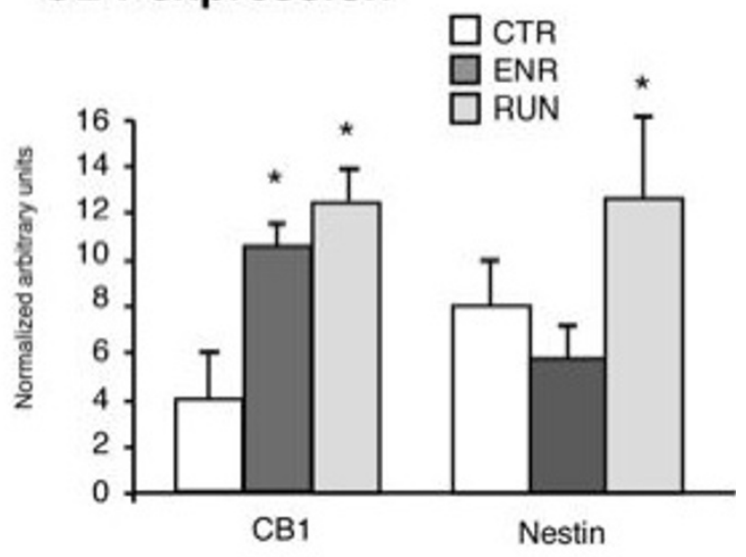

Figure 5 Activity induced effects. Running is known to enhance proliferation of cells in the dentate gyrus while enriched environment has a stronger effect on neuronal survival. We found that while RUN increased cell proliferation in WT mice, this was not the case in $\mathrm{CB} 1^{1}$ mice. $C B 1^{-/}$mice showed an increased baseline proliferation (A). In CB1\%ENR-induced increase in cell survival was abolished. (B) Both housing conditions resulted in an increase of CB1-mRNA in the hippocampus of wild type mice. The early neuronal marker Nestin was only increased in the RUN paradigm (C); ${ }^{*} \mathrm{p} \leq 0.05$. whether CB1 receptor expression would also be necessary to elicit the effects of RUN and ENR on adult neurogenesis

\section{Activity-induced neurogenesis is absent in $\mathrm{CB} 1^{-/}$- mice}

We next subjected female $\mathrm{CB}^{-/}$mice and their littermates to voluntary wheel running $\left(\mathrm{CB}^{-1 /} / \mathrm{RUN}\right.$ and WT/ RUN) for 10 consecutive days. We found that voluntary wheel running did not increase cell proliferation in $\mathrm{CB}^{-}$ mice as it did in WT mice. CB1 $1 /$ mice however, showed an increased baseline proliferation consistent with the findings presented in figure 6A (Fig. 5A; WT/CTR vs. CB1-//CTR: $1184 \pm 81$ vs. $2251 \pm 118 ; \mathrm{n}=5 ; \mathrm{p}=0.002$; WT/RUN vs. CB1 $1 / /$ RUN: $2197 \pm 74$ vs. $1772 \pm 68 ; n=5$; $\mathrm{p}=0.018)$. ENR primarily affects cell survival. In $\mathrm{CB} 1^{-/}$ mice the ENR-induced increase in cell survival was abolished (Fig. 5B; WT/ENR vs. CB1///ENR: $553 \pm 14$ vs. 362 $\pm 42 ; \mathrm{n}=5 ; \mathrm{p}=0.023)$. Taken together both results suggest that CB1-mediated mechanisms play an important role in mediating the behavior-induced regulation of adult hippocampal neurogenesis.

\section{Proliferation is increased but neurogenesis is reduced in $\mathrm{CB}^{-/-}$mice}

We now returned to evaluation of $\mathrm{CB} 1$ effects during the course of adult neurogenesis and how the affected neuronal maturation stages are influenced via the cannabinoid-mediated pathway. We therefore conducted a timecourse study in female untreated $\mathrm{CB}^{-/}$- mice compared to littermate controls (WT). At $24 \mathrm{~h}$ after BrdU the number of BrdU-positive cells was higher in the mutant mice (WT vs. CB1 $1^{--}: 2175 \pm 32$ vs. $2489 \pm 27 ; \mathrm{n}=5 ; \mathrm{p}=0.0042$; Fig. 6A) but was lower at 4 weeks after BrdU (WT vs. $\mathrm{CB1}^{-}: 368 \pm 21$ vs. $180 \pm 15 ; \mathrm{n}=5 ; \mathrm{p}=0.0024 ;$ Fig. 6 A). The percentage of NeuN-positive cells was also lower at 4 weeks after BrdU resulting in a net reduction of adult neurogenesis in the mutants (WT vs. $\mathrm{CB}^{-1-}: 82 \%$ vs. $66 \%$; $\mathrm{n}=5 ; \mathrm{p}=0.048$; Fig. $6 \mathrm{~A}$ ). When we looked at $24 \mathrm{~h}$ we found a relative reduction in the number of proliferative DCX-positive cells in the knock out animals (WT vs. $\mathrm{CB1}^{-1}: 81 \%$ vs. $75 \% ; \mathrm{n}=5 ; \mathrm{p}=0.063$; Fig. 6A). The contribution of type- 2 cells to the increase in proliferation in $\mathrm{CB}^{-/}$mice could not be further elucidated. GFAP-positive cells largely accounted for the initial increase in proliferation (WT vs. $\mathrm{CB1}^{-1}: 6 \%$ vs. $20 \%$; $=5 ; \mathrm{p}=0.001$; Fig. 6A). Additional studies will have to investigate to what degree these GFAP-positive cells include the radial glialike type- 1 cells. At an intermediate point in time at 7 days after BrdU injection, the proliferation in $\mathrm{CB}^{-/}$-animals was strongly reduced compared to controls, leading to the later reduction in adult net neurogenesis at 4 weeks after BrdU injection (WT vs. CB1 $1^{--}: 1683 \pm 65$ vs. $836 \pm$ $19 ; \mathrm{n}=5 ; \mathrm{p}=0.002 ;$ Fig. $6 \mathrm{~A}$ ). 


\section{A Time-course in $\mathrm{CB} 1^{-\%}$}

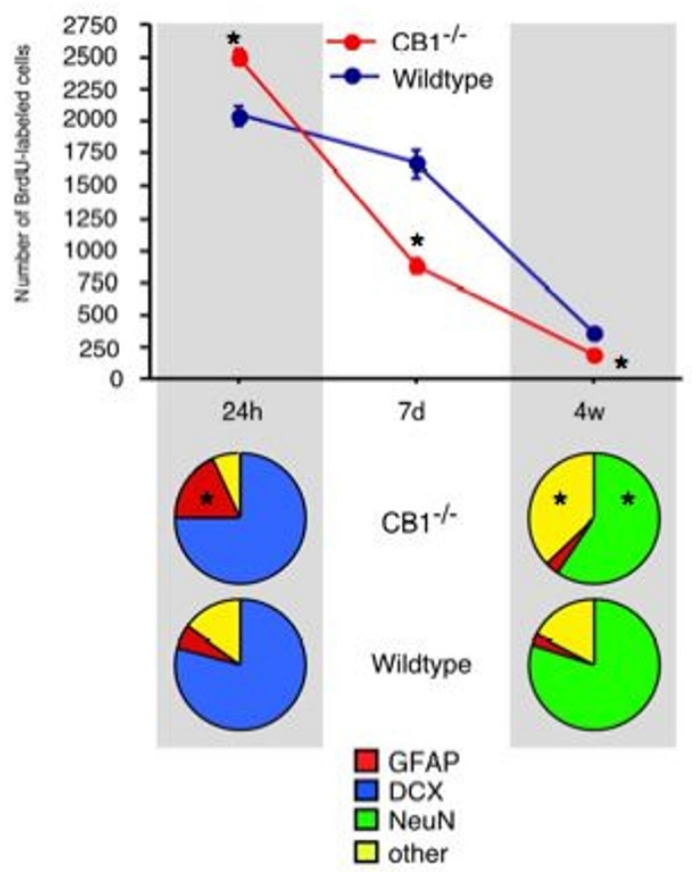

B Time-course after CB1 antagonist

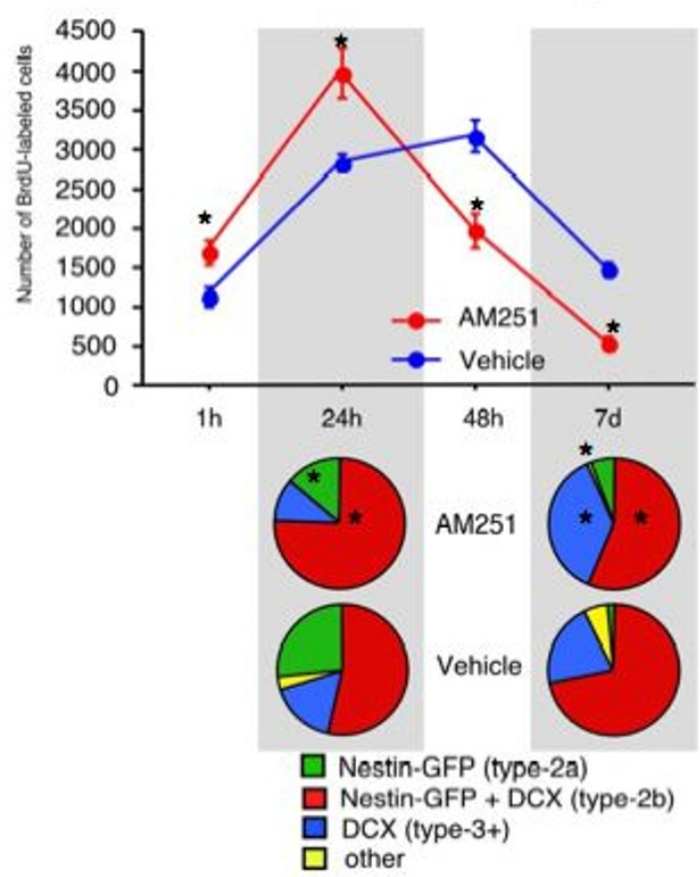

Figure 6 Effects of CB1 absence on neuronal maturation. By using animals at different points of time after BrdU injection a detailed time course of neuronal maturation has been established. At $24 \mathrm{~h}$ after BrdU the number of BrdU-positive cells was increased in the mutant mice but at $4 \mathrm{weeks}$ the number of BrdU-positive cells was reduced compared to the controls. The percentage of NeuN-positive cells was also reduced resulting in a net reduction of adult neurogenesis in the mutants. When we looked at the $24 \mathrm{~h}$ time point we found a relative reduction in the number of proliferative DCX-positive cells At an intermediate 7d time point, the increased proliferation in CB1\% animals had yielded to a strong reduction in BrdU positive cells compared to controls (A). To investigate early stages of neuronal maturation, we used Nestin-GFP-reporter mice and injected the CB1 antagonist AM251. At $1 \mathrm{~h}$ after BrdU application counts of BrdU-positive cells reflect S-phase entry. AM251-treatment increased the number of BrdU-positive cells compared to vehicle controls. At $24 \mathrm{~h}$ the numbers had roughly doubled, reflecting a completed cell cycle. Phenotypic analysis revealed that this increase was largely accounted by type-2b cells and later DCX-positive cells, whereas type-2a was even reduced. At $48 \mathrm{~h}$ control values for BrdU began to be higher than in the AM251-treated mice, leading to an almost two-fold reduction in AM251-treated mice at 7d (B); ${ }^{*} \leq \leq 0.05$.

\section{CB1 receptor antagonist $A M 251$ induces cell proliferation of DCX-positive precursor cells and reduces further differentiation}

These observations suggested that CB1-activity stimulates neurogenesis in particular from type- 2 cells onward, especially affecting the DCX-positive populations by accelerating development and promoting survival. To further study this shift from reduction to stimulation, which is already apparent in the time-course depicted in Fig. 6A, we conducted another experiment in untreated adult female Nestin-GFP-reporter mice to identify effects of CB1 antagonist AM251 on the intermediate precursor cell stages.
At $1 \mathrm{~h}$ after BrdU application counts of BrdU-positive cells reflect S-phase entry. As expected, AM251-treatment increased the number of BrdU-positive cells compared to vehicle controls (vehicle vs. AM251: $1142 \pm 28$ vs. $1674 \pm 27 ; \mathrm{n}=5 ; \mathrm{p}=0.038$; Fig. $6 \mathrm{~B}$ ). At $24 \mathrm{~h}$ the numbers had roughly doubled, reflecting a completed cell cycle. The relative difference between the groups was maintained at this point in time, confirming that CB1 receptor activity reduced cell proliferation from preventing S-phase entry onward (vehicle vs. AM251: $2810 \pm 35$ vs. $4048 \pm 120 ; n=5 ; \mathrm{p}=0.0042$; Fig. $6 \mathrm{~B}$ ). Phenotypic analysis revealed that this increase was largely accounted by type-2b cells, whereas type- 2 a was even reduced (vehi- 
cle vs. AM251: type- $2 \mathrm{~b} 58 \%$ vs. $77 \% ; \mathrm{n}=5 ; \mathrm{p}=0.032$; type-2a $27 \%$ vs. $12 \%$; $=5$; $\mathrm{p}=0.024$; Fig. $6 \mathrm{~B}$ ).

At $48 \mathrm{~h}$ AM251 values for BrdU began to be lower than in the vehicle-treated mice (vehicle vs. AM251: $3182 \pm 62$ vs. $2035 \pm 78 ; \mathrm{n}=5 ; \mathrm{p}=0.028$; Fig. $6 \mathrm{~B}$ ), leading to an almost two-fold reduction in AM251-treated mice at 7d (Fig. 6B; vehicle vs. AM251: $1627 \pm 18$ vs. $567 \pm 15 ; \mathrm{n}=5$; $\mathrm{p}=0.023)$. Most likely the BrdU positive cells in later maturation stages (depicted as "other") mainly account for the decrease (vehicle vs. AM251: other 3\% vs. $0.5 \%$; $n$ $=5 ; \mathrm{p}=0.002 ;$ Fig. 6B).

\section{Discussion}

In this study we have found substantial differences between THC and CBD treatment, supporting the previously reported disruption of memory formation by THC [41]. We did not find a suggestive association between CBD-mediated CB1 activity, learning performance in the water maze, and adult hippocampal neurogenesis. THC impaired cognitive and enhanced locomotor function but had no effect on neurogenesis, when given chronically. The learning phenotype in the Morris water maze did not correlate with the neurogenesis phenotype. Taken together, both THC and CBD effects on this type of hippocampus-dependent function cannot be linked to adult neurogenesis in a straightforward way. This discrepancy between functional and cellular hippocampal features had not yet been shown for THC or CBD, but the phenomenon of divergence between learning paradigms and neurogenesis is known from other studies (reviewed in [42]). When neurogenesis was blocked by focal $\mathrm{x}$-radiation the mice that had been exposed to an enriched environment still performed better in the Morris water maze than the mice housed in standard cages. Since enriched environment enhances the survival of newly generated neurons, the investigators claimed separate effects of the enriched environment on neurogenesis and on spatial learning [43]. Other groups showed that hippocampal irradiation immediately before the test had no effect, while irradiation days before the test impaired long-term memory in the water maze, indicative of a critical time window [44].

We showed that CBD increased neurogenesis at the survival stage 4 weeks after BrdU injection. Similar to the neuronal survival effect of $\mathrm{CBD}$ it has been reported, that the synthetic non-selective cannabinoid agonist WIN$55,212-2$ restored the physiologically decreased levels of adult neurogenesis in aged rats [45]. In the current study we have studied young adult mice, but it might be worthwhile to investigate in further studies the CBD effect in aged animals. CBD is known to be beneficial in schizophrenia or schizophrenic-like behaviour [17], where patients show a decrease in hippocampal volume and neurogenesis might be impaired $[17,46]$. CBD has some antipsychotic properties [47]. Moreover, smoking some strains of cannabis containing relatively more CBD, in addition to THC, appears to be more protective against the psychotic symptoms induced by THC alone [48].

A study by Boucher et al. has shown that THC impaired spatial memory and reversal learning, even in animals that received a THC pretreatment, indicating that although tolerance to the effects of THC on neuronal activity in the prefrontal cortex was reported, cannabinoid-induced memory impairment in these animals persisted [7]. Although we could only test our animals at one time point, including the information of tolerance resistance to THC from the reference mentioned above makes us confident that no acute or tolerance effects were present during our testing phase.

Taken together, the findings suggest diverse effects of the cannabinoid system on memory and cellular plasticity. These effects cannot be plainly categorized into impairing or enhancing effects of cannabinoid activation or deactivation [49]. The same might be true for the finding that THC increased the performance in the rotarod test. CB1 activation in the cerebellum by intra-cerebellar THC injection led to locomotor deficits [50]. Moreover, stimulation of cerebellar CB1 receptors with the agonists CP55,940 and HU-210 impaired rotarod performance [51]. THC injected intraperitoneally on the other hand failed to provoke motor coordination disturbances in wild type B6/CBA mice [52]. The route of administration seems to be a key difference between this one and the other studies. CB1 receptors were activated in all relevant brain regions and the local concentration of THC in a given brain structure was lower than when administered directly into the cerebellum [52]. In our study the mice took up the THC via the food, which led to improved rotarod performance. In the light of therapeutically targeting locomotor dysfunction with cannabinoids this finding might be notable. The therapeutic potential of the cannabinoids was also investigated in neurological diseases such as multiple sclerosis, Gilles de La Tourette syndrome, Parkinson and Huntington disease that all include locomotor disabilities [53]. Although the efficacy was not always clearly established, the undesirable effects observed were generally mild and well tolerated [54]. The drugs used to treat symptoms of multiple sclerosis (Sativex, contains THC and CBD) failed to change the neuropathological hallmarks of the disease. Patients reported only minor changes in memory loss, while improvements in locomotor and spasticity and neuropathic pain were dominant [55]. Experiments with THC and CBD in different concentrations might help to unravel the complex pattern of such treatments and should, as our results suggest, include measures of adult neurogenesis. 
The neurogenic effect of CBD was not found in $\mathrm{CB} 1^{-/}$ animals. Although CBD has low affinity to CB1 and its effects are often mediated via non-CB receptors (e.g. the vanilloid receptor) at least three other studies support that cannabidiol effects were CB1 receptor-dependent $[19,56,57]$. It might not be the only or usual mode of action, but with regard to enhanced adult hippocampal neurogenesis, CBD at least partially acts through the CB1 receptor. This result prompted us to investigate $\mathrm{CB} 1$ dependent regulation of neurogenesis utilizing CB1 receptor knock out animals as well as the $\mathrm{CB} 1$ receptor antagonist AM251 in Nestin-GFP-reporter mice.

In female $\mathrm{CB}^{-/}$mice on a $\mathrm{C} 57 \mathrm{BL} / 6$ background we found increased proliferation $24 \mathrm{~h}$ after BrdU injection and decreased net-neurogenesis (7 days and 4 weeks after BrdU injection). Jin and colleagues reported impaired progenitor cell proliferation in $\mathrm{CB} 1^{-/-}$mice but found contradicting increases with pharmacological CB1 antagonists SR141716A and AM251 [30,58]. We did not observed such discrepancy. The time point of analysis in the Jin et al. study was 3 days after BrdU injection. Thus, they might not have detected the most acute effects. Using the same compound AM251 on wild type mice, we got different results at 7 days after BrdU injection. Although we observed an increase of BrdU-labeled cells at $1 \mathrm{~h}$ and $24 \mathrm{~h}$, which would be in line with the findings by Jin et al., we found a decrease in BrdU-labeled cells at $48 \mathrm{~h}$ and 7 days. When phenotyped, DCX-positive cells accounted for the increase in proliferation at early time points, but at late time points fewer DCX- and more Nestin-positive cells were present indicating that maturation was impaired at the DCX-stage. This supports our data, that CB1 stimulation or blockage had different effects on neuronal progenitor proliferation and differentiation or maturation. The same pro-proliferative effect of AM251 at $24 \mathrm{~h}$ after BrdU injection have also been observed by Hill et al. in rats [59].

One notable difference between the study of Jin et al. and other studies (including ours) was their use of a CB11- strain bred onto the CD1 background [60]. We have previously shown that CD1 show a very unusual pattern of baseline adult neurogenesis. Despite lower levels of proliferation compared to $\mathrm{C} 57 \mathrm{BL} / 6$ they actually achieve high levels of net neurogenesis since survival exceeds any other strain investigated so far [61]. Another difference between the studies might have been the use of male vs. female mice since a recent report demonstrated differences in CB1 receptor abundance in the hippocampus between female and male mice [62]. Unfortunately Jin et al. did not report the gender examined in their studies. On the other hand, receptor abundance per se does not allow strong conclusions about receptor activity.

In addition, we show that the time point of measurement is critical when assessing the effects of the antago- nists. Our findings imply, that CB1 receptor activity would increase proliferation of type-1/2a, reduce proliferation of type- $2 b / 3$ but accelerate maturation from these cells and lead to a net reduction of adult neurogenesis. Consequently, the increase observed in the Jin et al. study after 3 days of AM251 in parallel to 3 days of BrdU is likely to actually reflect a mix of increases and decreases, which can only be untangled with a different BrdU injection protocol and a distinction of the different precursor cell types.

CB1 receptors are expressed in the course of neuronal development but they are present on all precursor cells, beginning with the radial glia-like type-1 cells [23]. CB1 expression appears to increase with differentiation, an observation that has also been made in embryonic cortical development [63]. Together with our previous data on wild type mice [40] these data indicate that CB1 is expressed by cells that are primarily affected by activitydependent regulation of adult hippocampal neurogenesis. We could consequently show that this type of regulation is impaired, if the CB1 receptor is absent. Keeney at al. have shown that the CB1 antagonist Rimonabant (SR141716) decreased running activity in C57Bl/6 female mice when injected for 9 consecutive days at the peak of running [64]. The situation in the knock out animal in our study is different, since CB1 is absent constitutively and not only at the peak of running like in the Keeney et al. study. It is also notable that SR141716 has different effects on neurogenesis than the absence of CB1 [30]. We measured running performance as the distance run per day for 10 consecutive days. As long as running the same distance is indicative of a similar stimulus for neurogenesis, the conditions should have been the same for $\mathrm{CB} 1^{-/-}$ and wild type mice. In the hippocampus of wild type mice we found an upregulation of CB1 receptor mRNA in the ENR and RUN mice along with an increase in Nestin mRNA only in the RUN paradigm. This is in line with studies reporting an increase in density of $\mathrm{CB} 1$ receptors in the hippocampus after voluntary wheel running. When AM251 was administered, activity-induced neurogenesis was impaired [65]. This result also supports our findings that activity-induced neurogenesis is absent in $\mathrm{CB} 1 \%$ mice. In contrast, a study using male mice that ran over a period of 6 weeks, $\mathrm{CB} 1^{-/}$animals covered less distance but showed greater numbers of DCX-expressing cells in the dentate gyrus indicating that a running-phenotype can be discovered after a prolonged running period [66]. Another study reported that CB1 receptor sensitivity in the striatum increased after voluntary wheel running [67]. In the light of therapeutic interventions targeting the cannabinoid system, increasing the receptor by simple running might be of interest.

The putative contribution of new neurons to hippocampal function has recently become increasingly 
clearer. Neurogenesis and specific aspects of learning (temporal separation, contextual integration, flexibility of relearning, and integration of novelty) $[34,68,69]$ have been linked and a role in affective behavior has been described [70,71]. Jiang and colleagues have suggested that the CB1-mediated effects of HU210 on adult neurogenesis might have anxiolytic and anti-depressant-like consequences [25]. It might thus be that the cannabinoiddependent regulation of adult neurogenesis is more relevant for the emotional than for the cognitive aspects of hippocampal function.

\section{Conclusions}

In this study we have shown that (1) exogenous cannabinoids THC and CBD differ in their effects on spatial learning and adult neurogenesis. (2) CBD did not impair learning but increased adult neurogenesis despite (3) a CBD-induced reduction in cell proliferation. We found (4) the pro-neurogenic effect of CBD to be dependent on the CB1 receptor, which (5) shows a widespread expression over the entire dentate gyrus, including the neuronal precursor cells. Similarly, (6) the pro-neurogenic effect of environmental enrichment and voluntary wheel running depended on the presence of the $\mathrm{CB} 1$ receptor. Along the same line, (7) voluntary wheel running increased CB1 receptor mRNA in the hippocampus. We observed that (8) in the absence of CB1 receptors, cell proliferation was increased and neuronal differentiation reduced.

Although it has been reported that CBD binds with a low affinity to the $\mathrm{CB} 1$ receptor, its mode of action on neurogenesis seems to involve the CB1 receptor since $\mathrm{CBD}$ had no effect on $\mathrm{CB}^{-/}$animals. This prompted us to investigate the CB1 dependent regulation of neurogenesis using a genetic model and an antagonist. Taken together, our results indicate that the CB1 receptor appears to play an important role in modulating adult hippocampal neurogenesis. More specifically, CB1 affects the stages of adult neurogenesis that involve intermediate highly proliferative progenitor cells (type- 2 and type- 3 cells) and the survival and maturation of the new neurons. While these results are mostly in line with previous results on CB1 function in adult neurogenesis (reviewed in [13]), they also go beyond what was known since our data elucidate the time-course of this action and reveal a contribution of $\mathrm{CB} 1$ to activity-dependent regulation. Although others and we found CB1 receptor expression on precursor cells, the effects on cannabinoids on neurogenesis might still be indirect as well.

\section{Materials and methods \\ Animals}

The generation of CB1-/- mice on a C57Bl/6 background has been described elsewhere [72]. The animals were kindly provided by Roland Martin, National Institutes of
Health, Bethesda. The control group consisted of agematched littermates. Since we carried out heterozygote breeding, we genotyped the progeny by PCR using the following primers

3'AAGAACGAGATCAGCAGCCTCTGTT5'; 3'GGATTCAGAATCATGAAGCACTCCA5'.

The experiments measuring the early stages of neurogenesis were performed in transgenic mice expressing the green fluorescent protein (GFP) driven by regulatory elements of the Nestin gene, Nestin-GFP mice [73].

All the animals were held in the same room with a consistent 12-hour-light-dark-cycle and were fed with the standard or supplemented food and water ad libitum. To estimate the daily food intake, animals and food were weighted every $3^{\text {rd }}$ day for the whole period of the experiment (see additional file 1, 2).

All applicable local and federal regulations on animal welfare were followed. The animal protocol was approved by "Landesamt für Arbeitsschutz, Gesundheitsschutz und technische Sicherheit Berlin (LaGetSi)".

\section{Experimental design}

Thirty female $\mathrm{CB}^{-/}$and their littermates (WT) mice were randomly assigned to either enriched (CB1-//ENR; WT/ENR) or standard housing (CB1/-/CTR; WT/CTR) or standard cages that were equipped with a running wheel (CB1/-/RUN; WT/RUN). RUN-assigned animals had unlimited access to the running wheel (Tecniplast, Hohenpeißenberg, Germany) for 10 days. The enriched housing in which the animals lived for 4 weeks was similar to our previous studies [74]. Briefly, it consisted of a spacious cage of approximately $80 \times 80 \mathrm{~cm}$ floor area, complemented with a re-arrangeable system of tubes, a cardboard box house and a crawling ball. The ENR and CTR animals were housed in groups of 5 , in the RUN cages 2 animals lived together. To evaluate CB1 mRNA expression changes by activity, we subjected additional 5 female $\mathrm{C} 57 \mathrm{Bl} / 6$ to either experimental condition (RUN, ENR, CTR).

In a different set of experiments, 30 female wild-type mice were housed in standard cages and fed with either a diet supplemented with THC or CBD or without any drug (CTR) for 6 weeks (chronic treatment). Ten CB1 knockout mice were fed with either a diet supplemented with CBD or standard food.

After treatment 10 animals of each group were tested in the Morris water maze for spatial memory performance and in the rotarod for locomotor functions. All remaining mice received daily intraperitoneal injections of Bromdesoxyuridin BrdU (50 $\mu \mathrm{g} / \mathrm{kg}$ body weight, Sigma) for either 1 day or 5 consecutive days and were killed either 24 hours (proliferation) or 4 weeks (survival) after the last BrdU injection. At the starting point of all experiments the age was 6-8 weeks. The behavioral testing occurred 6 
weeks later so that the animals were at least 12 weeks old when the testing started and 16 weeks when the survival time point of adult neurogenesis was assessed.

To analyze the chronic impact of the cannabinoids on the early stages of neuronal development, we utilized transgenic animals where the Nestin promotor is linked with an eGFP-construct emitting green fluorescence [73]. Twenty Nestin-GFP female animals were fed for 6 weeks with a THC-rich or CBD-rich or standard diet (see below). The antagonist AM251 compared to vehicle injections (Torisolve, Tocris) was used on 10 Nestin-GFPreporter mice to evaluate the impact of $\mathrm{CB} 1$ at the early stages of neurogenesis, as described previously [36]. In parallel, five female $\mathrm{CB} 1^{-/-}$and their littermates (WT) each received BrdU for either 1 day or 5 consecutive days and were killed either 24 hours (proliferation), 7 days or 4 weeks (survival) after the last BrdU injection

\section{Cannabinoid and antagonist treatment}

THC-rich or CBD-rich plant extract was kindly provided by GW-Pharmaceuticals, UK. The plant extracts were incorporated into a standard diet by ResearchDiet, USA at the concentration of either $41.2 \%$ for active THC or $38.8 \%$ for active CBD. The diets were colour -labelled for easier handling.

CB1 antagonist AM251 (Tocris) was injected intraperitoneally at $0.25 \mathrm{mg} / \mathrm{kg}$ in Tocrisolve $(0.5 \mu \mathrm{g} / \mu \mathrm{l}$ in $100 \mu \mathrm{l}$ per animal).

\section{Immunohistochemistry}

Animals were deeply anesthetized with ketamine and perfused transcardially with cold $4 \%$ paraformaldehyde in $0.1 \mathrm{M}$ phosphate buffer, $\mathrm{pH}$ 7.4. The brains were dissected from the skulls and were postfixed overnight. Before sectioning from a dry-ice-cooled copper block on a sliding microtome (Leica, Bensheim), the hemispheres were transferred to $30 \%$ sucrose in $0.1 \mathrm{M}$ phosphate buffer, $\mathrm{pH} 7.4$, until they had sunk. Hemispheres were cut in the coronal plane in $40 \mu \mathrm{m}$ thick sections and cryo-protected. The level of generation of new cells was determined by the in vivo injection of BrdU, which incorporates during the $\mathrm{S}$-phase into the cell and thus labelled proliferating cells. BrdU labelled cells in the subgranular zone of the dentate gyrus in the hippocampus were quantified as described previously [69]. Briefly all labelled cells per dentate gyrus were counted in every $6^{\text {th }}$ section containing the hippocampus. For each animal 9 sections have been counted (both sides). The number was multiplied by six to estimate the total cell number per brain. For BrdU staining, DNA was denatured in $2 \mathrm{~N} \mathrm{HCL}$ for 30 minutes at $37^{\circ} \mathrm{C}$. Free-floating sections were than rinsed in $0.1 \mathrm{M}$ borate buffer, $\mathrm{pH} 8.5$, and thoroughly washed in tris-buffered saline (TBS), pH 7.4. To block endogenous peroxidase reactions, sections were pretreated with $0.6 \% \mathrm{H}_{2} \mathrm{O}_{2}$. The rat-anti-mouse- $\mathrm{BrdU}$ antibody (Harlan Seralab) was diluted 1:500 in TBS supplemented with $0.1 \%$ TritonX-100, $0.1 \%$ Tween 20 and $3 \%$ donkey serum (TBS-plus) and the sections were incubated overnight at $4^{\circ} \mathrm{C}$. After rinsing the sections in TBS and a blocking step in TBS-plus, an incubation step with the biotinylated secondary antibody (donkey-anti-rat, Vector) diluted 1:500 in TBS-plus followed. ABC reagent (Vectastain Elite, Vector Laboratories) was applied for $1 \mathrm{~h}$ at a concentration of $9 \mu \mathrm{l} / \mathrm{ml}$ for each reagent. Diaminobenzidine (DAB, Sigma) was used as a chromogen at the concentration of $0.25 \mathrm{mg} / \mathrm{ml}$ in TBS with $0.01 \% \mathrm{H}_{2} \mathrm{O}_{2}$ and $0.04 \%$ nickelchloride followed by rinsing with tap water and TBS. The sections were mounted on slides and coverslipped with Neomount. To phenotype the proliferating cells, we used triple staining for BrdU and a combination of maturation markers as applicable. A total of randomly selected 50 BrdU-positive cells per animal were phenotyped. Knowing the absolute number of BrdU cells in a given brain, we were able to convert the percentage of cells expressing one of the maturation markers and BrdU into the absolute number of cells per phenotype in the whole brain. All counting were done blinded by the same researcher as described previously $[38,69]$. The primary antibodies were applied in the following concentrations: BrdU (1:500, Harlan Seralab), anti-Doublecortin (DCX, 1:200, Santa Cruz Biotechnologies), anti-Calretinin (1:250, Santa Cruz), anti-GFP (to visualize Nestin, 1:500, Swant), anti-NeuN (1:100, Chemicon), anti-GFAP (1:250, Chemicon), anti-CB1 (1:250, LifeBioscience). Secondary antibodies were anti-goat, anti-rabbit, anti-mouse, and anti-rat (1:250, Jackson Laboratories) directly coupled to a fluorochrome for confocal analysis. To test for statistical significant differences $(\mathrm{p}=0.05)$ between two groups, we used the non-parametrical Mann-Whitney-U-test.

\section{RNA isolation and RT-PCR}

RNA was isolated with an RNeasy mini isolation kit according to the manufactures instructions (Qiagen, Hilden, Germany). CB1 and Nestin content in $1 \mu \mathrm{g}$ RNA per sample was measured using the QuantiFast SYBR Green RT-PCR Kit according to the manufactures instructions (Qiagen, Hilden, Germany). We used the following primer pairs generated with primer3 software: CB1: forward CTGGTTCTGATCCTGGTGGT, reverse TGTCTCAGGTCCTTGCTCCT; Nestin: forward TTGAGGCCTCCAGAAGAAGA, reverse GCCATCTGCTCCTCTTTCAC. The RNA amount was normalized to the housekeeping gene GAPDH. Statistical analysis has been done using the non-parametrical Mann-Whitney-U test between two groups. PCR was performed using an OPTICON II (BioRad, Munic, Germany). 


\section{Behavioral Tests}

The Morris water maze (MWM) test is widely used to test rodents for spatial memory performance [75]. We followed the protocol revised by Wolfer and Lipp [76]. Six trials of training, each maximally lasting 2 minutes, were given each day. Latencies to reach the platform and swim paths were recorded with an automatic video tracking system (Ethovision, Noldus, Utrecht, Netherlands).

Animals were exposed to the MWM that contained an escape platform submerged $1 \mathrm{~cm}$ below the water line. The platform was kept at a constant location within the pool during the first 3 days of training. On the morning of the $4^{\text {th }}$ day the escape platform was placed in the quadrant opposite to the first target quadrant to start the reversal learning task for two more days. The first trial of the reversal period was analyzed as "probe trial". To control for parameters that are not hippocampus-dependent such as vision impairments, the task was afterwards repeated with a visible platform. To evaluate learning of the spatial location of the platform, latencies to reach the platform (in seconds) and total length of swim path (in pixels converted to $\mathrm{cm}$ ) were compared between trials. Additionally, the time spent in the target quadrant on the probe trials was used as an indicator of targeted searching for the platform. During the reversal learning, time spent in quadrant 1 (location of the platform during initial training) versus quadrant 3 (location of the platform during reversal training) was measured.

To analyze performance in the MWM test, we performed a repeated measure ANOVA test of the daily means. Analysis of the differences between the groups in the parameters escape latency, and distance moved per day, using the Fisher post-hoc-test, if applicable.

To test general locomotor functions and fitness of the animals, a rotarod was used. The mice were placed on a slowly rotating rod $(20 \mathrm{rpm})$ and a stopwatch was started. The rod accelerated with $20 \mathrm{rpm}$. When the mice overbalanced and touched the ground, the stopwatch stopped automatically. Each animal performed 4 trials.

\section{Additional material}

\footnotetext{
Additional file $\mathbf{1}$ Weight gain and food intake. The two graphs show the food intake and weight gain (g) during the whole period of the experiment of 6 weeks. In the beginning of the experimental period, some variances could be seen in the food intake between the groups at certain days. At 6 weeks, when the analysis started, all groups reached a similar level of food intake and weight in average.

Additional file $\mathbf{2}$ Weight gain and food intake. The two graphs show the food intake and weight gain (g) during the whole period of the experiment of 6 weeks. In the beginning of the experimental period, some variances could be seen in the food intake between the groups at certain days. At 6 weeks, when the analysis started, all groups reached a similar level of food intake and weight in average.
}

\section{Competing interests}

The authors declare that they have no competing interests.

\section{Authors' contributions}

SAW has designed the study, carried out the in vivo experiments, did statistical analysis and drafted the manuscript

ABS participated in the design of the study and did the behavioral analysis

KF and PLG carried out the CB1 staining and prepared Fig. 4

ST revised the manuscript

AM carried out confocal analysis

TPW participated in the draft of the manuscript and carried out the immunoassays

GRR carried out cell culture work (data not shown)

AM carried out the RNA analysis

OU worked on the manuscript

GK supervised the experimental design, prepared figures and substantially contributed to the drafting, writing and revision of the manuscript

All authors read and approved the final manuscript.

\section{Author Details}

${ }^{1}$ Max Delbrück Center for Molecular Medicine (MDC) Berlin-Buch, and Volkswagenstiftung Research Group, Department of Experimental Neurology, Charité University Medicine, Berlin, Germany, ${ }^{2}$ Institute of Anatomy, University of Zurich, Zurich, Switzerland, ${ }^{3}$ National Institute of Psychiatry "Ramón de la Fuente Muñiz", Neuropharmacology Department, Calz. México-Xochimilco 101, 14370 México, D.F. México and ${ }^{4}$ CRTD - Center for Regenerative Therapies Dresden, Dresden, Germany

Received: 22 September 2009 Accepted: 17 June 2010

Published: 17 June 2010

References

1. Martin BR, Mechoulam R, Razdan RK: Discovery and characterization of endogenous cannabinoids. Life Sci 1999, 65:573-595.

2. Mechoulam R, Shohami E: Endocannabinoids and traumatic brain injury. Mol Neurobiol 2007, 36:68-74.

3. Mechoulam R, Spatz M, Shohami E: Endocannabinoids and neuroprotection. SciSTKE 2002, 2002:re5.

4. Kogan NM, Mechoulam R: Cannabinoids in health and disease. Dialogues Clin Neurosci 2007, 9:413-430.

5. Hollister LE: Health aspects of cannabis: revisited. Int $J$ Neuropsychopharmacol 1998, 1:71-80.

6. Sarne Y, Mechoulam R: Cannabinoids: between neuroprotection and neurotoxicity. Curr Drug Targets CNS Neurol Disord 2005, 4:677-684.

7. Boucher AA, Vivier L, Metna-Laurent M, Brayda-Bruno L, Mons N, Arnold JC, Micheau J: Chronic treatment with Delta(9)-tetrahydrocannabinol impairs spatial memory and reduces zif268 expression in the mouse forebrain. Behav Pharmacol 2009, 20:45-55.

8. Kempermann G, Wiskott L, Gage FH: Functional significance of adult neurogenesis. Curr Opin Neurobiol 2004, 14:186-191.

9. Kempermann G, Kronenberg G: Depressed new neurons--adult hippocampal neurogenesis and a cellular plasticity hypothesis of major depression. Biol Psychiatry 2003, 54:499-503.

10. Reif A, Fritzen S, Finger M, Strobel A, Lauer M, Schmitt A, Lesch KP: Neural stem cell proliferation is decreased in schizophrenia, but not in depression. Mol Psychiatry 2006, 11:514-522.

11. Altman J: Autoradiographic study of degenerative and regenerative proliferation of neuroglia cells with tritiated thymidine. Exp Neurol 1962, 5:302-318

12. Bayer SA, Altman J: Principles of neurogenesis, neuronal migration, and neural circuit formation. In The Rat Nervous System Edited by: Paxinos G The Rat Nervous System: The Rat Nervous System; 1995:1079-1098.

13. Wolf SA, Ullrich O: Endocannabinoids and the brain immune system: new neurones at the horizon? J Neuroendocrino/ 2008, 20(Suppl 1):15-19.

14. Pertwee RG: Emerging strategies for exploiting cannabinoid receptor agonists as medicines. Br J Pharmaco/ 2009, 156:397-411.

15. Mechoulam R, Peters M, Murillo-Rodriguez E, Hanus LO: Cannabidiol-recent advances. Chem Biodivers 2007, 4:1678-1692.

16. Zuardi AW, Crippa JA, Hallak JE, Pinto JP, Chagas MH, Rodrigues GG, Dursun SM, Tumas V: Cannabidiol for the treatment of psychosis in Parkinson's disease. J Psychopharmacol 2009, 23:979-983.

17. Zuardi AW, Hallak JE, Dursun SM, Morais SL, Sanches RF, Musty RE, Crippa JA: Cannabidiol monotherapy for treatment-resistant schizophrenia. J Psychopharmacol 2006, 20:683-686. 
18. Hampson AJ, Grimaldi M, Axelrod J, Wink D: Cannabidiol and (-)Delta9tetrahydrocannabinol are neuroprotective antioxidants. Proc Nat/ Acad Sci USA 1998, 95:8268-8273.

19. Thomas A, Baillie GL, Phillips AM, Razdan RK, Ross RA, Pertwee RG: Cannabidiol displays unexpectedly high potency as an antagonist of CB1 and CB2 receptor agonists in vitro. Br J Pharmacol 2007, 150:613-623.

20. Harkany T, Guzman M, Galve-Roperh I, Berghuis P, Devi LA, Mackie K: The emerging functions of endocannabinoid signaling during CNS development. Trends Pharmacol Sci 2007, 28:83-92.

21. Aguado T, Monory K, Palazuelos J, Stella N, Cravatt B, Lutz B, Marsicano G, Kokaia Z, Guzman M, Galve-Roperh I: The endocannabinoid system drives neural progenitor proliferation. Faseb J 2005, 19:1704-1706.

22. Goncalves MB, Suetterlin P, Yip P, Molina-Holgado F, Walker DJ, Oudin MJ, Zentar MP, Pollard S, Yanez-Munoz RJ, Williams G, et al:: A diacylglycerol lipase-CB2 cannabinoid pathway regulates adult subventricular zone neurogenesis in an age-dependent manner. Mol Cell Neurosci 2008, 38:526-536.

23. Aguado T, Palazuelos J, Monory K, Stella N, Cravatt B, Lutz B, Marsicano G, Kokaia Z, Guzman M, Galve-Roperh I: The endocannabinoid system promotes astroglial differentiation by acting on neural progenitor cells. J Neurosci 2006, 26:1551-1561.

24. Mackowiak M, Chocyk A, Markowicz-Kula K, Wedzony K: Acute activation of CB1 cannabinoid receptors transiently decreases PSA-NCAM expression in the dentate gyrus of the rat hippocampus. Brain Res 2007, 1148:43-52.

25. Jiang W, Zhang Y, Xiao L, Van Cleemput J, Ji SP, Bai G, Zhang X: Cannabinoids promote embryonic and adult hippocampus neurogenesis and produce anxiolytic- and antidepressant-like effects. J Clin Invest 2005, 115:3104-3116.

26. Aguado T, Romero E, Monory K, Palazuelos J, Sendtner M, Marsicano G, Lutz B, Guzman M, Galve-Roperh I: The CB1 cannabinoid receptor mediates excitotoxicity-induced neural progenitor proliferation and neurogenesis. J Biol Chem 2007, 282:23892-23898.

27. Rueda D, Navarro B, Martinez-Serrano A, Guzman M, Galve-Roperh I: The endocannabinoid anandamide inhibits neuronal progenitor cell differentiation through attenuation of the Rap1/B-Raf/ERK pathway. $J$ Biol Chem 2002, 277:46645-46650.

28. Jessberger S, Zhao C, Toni N, Clemenson GD, Li Y, Gage FH: Seizureassociated, aberrant neurogenesis in adult rats characterized with retrovirus-mediated cell labeling. J Neurosci 2007, 27:9400-9407.

29. Jessberger S, Romer B, Babu H, Kempermann G: Seizures induce proliferation and dispersion of doublecortin-positive hippocampal progenitor cells. Exp Neurol 2005, 196:342-351.

30. Jin K, Xie L, Kim SH, Parmentier-Batteur S, Sun Y, Mao XO, Childs J, Greenberg DA: Defective adult neurogenesis in CB1 cannabinoid receptor knockout mice. Mol Pharmacol 2004, 66:204-208.

31. Kochman LJ, dos Santos AA, Fornal CA, Jacobs BL: Despite strong behavioral disruption, Delta9-tetrahydrocannabinol does not affect cell proliferation in the adult mouse dentate gyrus. Brain Res 2006, 1113:86-93

32. Huestis MA, Gorelick DA, Heishman SJ, Preston KL, Nelson RA, Moolchan $E T$, Frank RA: Blockade of effects of smoked marijuana by the CB1selective cannabinoid receptor antagonist SR141716. Arch Gen Psychiatry 2001, 58:322-328.

33. Kempermann G: Regulation of adult hippocampal neurogenesis implications for novel theories of major depression. Bipolar Disord 2002, 4:17-33

34. Garthe A, Behr J, Kempermann G: Adult-generated hippocampal neurons allow the flexible use of spatially precise learning strategies. PLOS ONE 2009, 4:e5464

35. Wolf SA, Steiner B, Akpinarli A, Kammertoens T, Nassenstein C, Braun A, Blankenstein T, Kempermann G: CD4-positive T lymphocytes provide a neuroimmunological link in the control of adult hippocampal neurogenesis. J Immunol 2009, 182:3979-3984.

36. Filippov V, Kronenberg G, Pivneva T, Reuter K, Steiner B, Wang LP, Yamaguchi M, Kettenmann H, Kempermann G: Subpopulation of nestinexpressing progenitor cells in the adult murine hippocampus shows electrophysiological and morphological characteristics of astrocytes. Mol Cell Neurosci 2003, 23:373-382.

37. Brandt MD, Jessberger S, Steiner B, Kronenberg G, Reuter K, Bick-Sander A, von der Behrens W, Kempermann G: Transient calretinin expression defines early postmitotic step of neuronal differentiation in adult hippocampal neurogenesis of mice. Mol Cell Neurosci 2003, 24:603-613.

38. Kempermann G, Jessberger S, Steiner B, Kronenberg G: Milestones of neuronal development in the adult hippocampus. Trends Neurosci 2004, 27:447-452.

39. Schmidt A, Haas SJ, Hildebrandt S, Scheibe J, Eckhoff B, Racek T, Kempermann G, Wree A, Putzer BM: Selective targeting of adenoviral vectors to neural precursor cells in the hippocampus of adult mice: new prospects for in situ gene therapy. Stem Cells 2007, 25:2910-2918.

40. Kronenberg G, Reuter K, Steiner B, Brandt MD, Jessberger S, Yamaguchi M, Kempermann G: Subpopulations of proliferating cells of the adult hippocampus respond differently to physiologic neurogenic stimuli. J Comp Neurol 2003, 467:455-463.

41. Heyser CJ, Hampson RE, Deadwyler SA: Effects of delta-9tetrahydrocannabinol on delayed match to sample performance in rats: alterations in short-term memory associated with changes in task specific firing of hippocampal cells. J Pharmacol Exp Ther 1993, 264:294-307.

42. Leuner B, Gould E, Shors TJ: Is there a link between adult neurogenesis and learning? Hippocampus 2006, 16:216-224.

43. Meshi D, Drew MR, Saxe M, Ansorge MS, David D, Santarelli L, Malapani C, Moore H, Hen R: Hippocampal neurogenesis is not required for behavioral effects of environmental enrichment. Nat Neurosci 2006 9:729-731.

44. Snyder JS, Hong NS, MCDonald RJ, Wojtowicz JM: A role for adult neurogenesis in spatial long-term memory. Neuroscience 2005, 130:843-852.

45. Marchalant Y, Brothers HM, Wenk GL: Cannabinoid agonist WIN-55,212-2 partially restores neurogenesis in the aged rat brain. Mol Psychiatry 2009, 14:1068-1069

46. Steen RG, Mull C, McClure R, Hamer RM, Lieberman JA: Brain volume in first-episode schizophrenia: systematic review and meta-analysis of magnetic resonance imaging studies. Br J Psychiatry 2006, 188:510-518.

47. Zuardi AW, Crippa JA, Hallak JE, Moreira FA, Guimaraes FS: Cannabidiol, a Cannabis sativa constituent, as an antipsychotic drug. Braz J Med Biol Res 2006, 39:421-429.

48. Morgan CJ, Curran HV: Effects of cannabidiol on schizophrenia-like symptoms in people who use cannabis. Br J Psychiatry 2008 192:306-307.

49. Abush H, Akirav I: Cannabinoids modulate hippocampal memory and plasticity. Hippocampus 2009 in press

50. Dar MS: Cerebellar CB(1) receptor mediation of Delta(9)-THC-induced motor incoordination and its potentiation by ethanol and modulation by the cerebellar adenosinergic $\mathrm{A}(1)$ receptor in the mouse. Brain Res 2000, 864:186-194.

51. DeSanty KP, Dar MS: Cannabinoid-induced motor incoordination through the cerebellar $\mathrm{CB}(1)$ receptor in mice. Pharmacol Biochem Behav 2001, 69:251-259.

52. Lorivel T, Hilber P: Motor effects of delta $9 \mathrm{THC}$ in cerebellar Lurcher mutant mice. Behav Brain Res 2007, 181:248-253.

53. Ben Amar M: Cannabinoids in medicine: A review of their therapeutic potential. J Ethnopharmacol 2006, 105:1-25.

54. Carter GT, Ugalde V: Medical marijuana: emerging applications for the management of neurologic disorders. Phys Med Rehabil Clin N Am 2004, 15:943-954. ix

55. Barnes MP: Sativex: clinical efficacy and tolerability in the treatment of symptoms of multiple sclerosis and neuropathic pain. Expert Opin Pharmacother 2006, 7:607-615.

56. Capasso R, Borrelli F, Aviello G, Romano B, Scalisi C, Capasso F, Izzo AA: Cannabidiol, extracted from Cannabis sativa, selectively inhibits inflammatory hypermotility in mice. Br J Pharmacol 2008, 154:1001-1008.

57. Bitencourt RM, Pamplona FA, Takahashi RN: Facilitation of contextual fear memory extinction and anti-anxiogenic effects of AM404 and cannabidiol in conditioned rats. Eur Neuropsychopharmacol 2008, 18:849-859.

58. Kim SH, Won SJ, Mao XO, Ledent C, Jin K, Greenberg DA: Role for neuronal nitric-oxide synthase in cannabinoid-induced neurogenesis. J Pharmacol Exp Ther 2006, 319:150-154.

59. Hill MN, Kambo JS, Sun JC, Gorzalka BB, Galea LA: Endocannabinoids modulate stress-induced suppression of hippocampal cell 

2006, 24:1845-1849.

60. Ledent C, Valverde O, Cossu G, Petitet F, Aubert JF, Beslot F, Bohme GA, Imperato A, Pedrazzini T, Roques BP, et al:: Unresponsiveness to cannabinoids and reduced addictive effects of opiates in CB1 receptor knockout mice. Science 1999, 283:401-404.

61. Kempermann G, Kuhn HG, Gage FH: Genetic influence on neurogenesis in the dentate gyrus of adult mice. Proc Natl Acad Sci USA 1997, 94:10409-10414.

62. Reich CG, Taylor ME, McCarthy MM: Differential effects of chronic unpredictable stress on hippocampal CB1 receptors in male and female rats. Behav Brain Res 2009, 203:264-269.

63. Vitalis T, Laine J, Simon A, Roland A, Leterrier C, Lenkei Z: The type 1 cannabinoid receptor is highly expressed in embryonic cortical projection neurons and negatively regulates neurite growth in vitro. Eur J Neurosci 2008, 28:1705-1718.

64. Keeney BK, Raichlen DA, Meek TH, Wijeratne RS, Middleton KM, Gerdeman $\mathrm{GL}$, Garland T Jr: Differential response to a selective cannabinoid receptor antagonist (SR141716: rimonabant) in female mice from lines selectively bred for high voluntary wheel-running behaviour. Behav Pharmacol 2008, 19:812-820.

65. Hill MN, Titterness AK, Morrish AC, Carrier EJ, Lee TT, Gil-Mohapel J, Gorzalka BB, Hillard CJ, Christie BR: Endogenous cannabinoid signaling is required for voluntary exercise-induced enhancement of progenitor cell proliferation in the hippocampus. Hippocampus 2009, 20(4):513-23.

66. Dubreucq S, Koehl M, Abrous DN, Marsicano G, Chaoul off F: CB1 receptor deficiency decreases wheel-running activity: Consequences on emotional behaviours and hippocampal neurogenesis. Exp Neurol 2010, 224(1):106-113.

67. De Chiara V, Errico F, Musella A, Rossi S, Mataluni G, Sacchetti L, Siracusano A, Castelli M, Cavasinni F, Bernardi G, et al:: Voluntary exercise and sucrose consumption enhance cannabinoid CB1 receptor sensitivity in the striatum. Neuropsychopharmacology 35:374-387.

68. Clelland CD, Choi M, Romberg C, Clemenson GD, Fragniere A, Tyers P, Jessberger S, Saksida LM, Barker RA, Gage FH, Bussey TJ: A functional role for adult hippocampal neurogenesis in spatial pattern separation. Science 2009, 325:210-213.

69. Wiskott L, Rasch MJ, Kempermann G: A functional hypothesis for adult hippocampal neurogenesis: avoidance of catastrophic interference in the dentate gyrus. Hippocampus 2006, 16:329-343.

70. Bergami M, Rimondini R, Santi S, Blum R, Gotz M, Canossa M: Deletion of TrkB in adult progenitors alters newborn neuron integration into hippocampal circuits and increases anxiety-like behavior. Proc Natl Acad Sci USA 2008, 105:15570-15575.

71. Revest JM, Dupret D, Koehl M, Funk-Reiter C, Grosjean N, Piazza PV, Abrous DN: Adult hippocampal neurogenesis is involved in anxiety-related behaviors. Mol Psychiatry 2009, 10:959-67.

72. Zimmer A, Zimmer AM, Hohmann AG, Herkenham M, Bonner TI: Increased mortality, hypoactivity, and hypoalgesia in cannabinoid CB1 receptor knockout mice. Proc Natl Acad Sci USA 1999, 96:5780-5785.

73. Yamaguchi M, Saito H, Suzuki M, Mori K: Visualization of neurogenesis in the central nervous system using nestin promoter-GFP transgenic mice. Neuroreport 2000, 11:1991-1996.

74. Van Praag H, Kempermann G, Gage FH: Running increases cell proliferation and neurogenesis in the adult mouse dentate gyrus. Nat Neurosci 1999, 2:266-270.

75. Morris RG, Garrud P, Rawlins JN, O'Keefe J: Place navigation impaired in rats with hippocampal lesions. Nature 1982, 297:681-683.

76. Wolfer DP, Muller U, Stagliar M, Lipp HP: Assessing the effects of the 129/ Sv genetic background on swimming navigation learning in transgenic mutants: a study using mice with a modified beta-amyloid precursor protein gene. Brain Res 1997, 771:1-13.

doi: $10.1186 / 1478-811 X-8-12$

Cite this article as: Wolf et al., Cannabinoid receptor CB1 mediates baseline and activity-induced survival of new neurons in adult hippocampal neurogenesis Cell Communication and Signaling 2010, 8:12

\section{Submit your next manuscript to BioMed Central and take full advantage of:}

- Convenient online submission

- Thorough peer review

- No space constraints or color figure charges

- Immediate publication on acceptance

- Inclusion in PubMed, CAS, Scopus and Google Scholar

- Research which is freely available for redistribution 